\title{
The Stability of Gold Nanoparticles-Prussian Blue Based Sensors for Biosensor Applications in Clinical Diagnosis
}

\author{
Kewarin Phonklam, M.Sc. , Piromya Thongkhao, B.Sc. ${ }^{1}$, Tonghathai Phairatana, Ph.D. ${ }^{1,2,3}$
}

'Department of Biomedical Sciences and Biomedical Engineering, Faculty of Medicine, Prince of Songkla University, Hat Yai, Songkhla 90110, Thailand.

${ }^{2}$ Institute of Biomedical Engineering, Faculty of Medicine, Prince of Songkla University, Hat Yai, Songkhla 90110, Thailand.

${ }^{3}$ Medical Science Research and Innovation Institute, Prince of Songkla University, Hat Yai, Songkhla 90110, Thailand.

Received 10 September 2021 • Revised 18 November 2021 • Accepted 22 November 2021 • Published online 20 January 2022

\begin{abstract}
:
Objective: Many medical biosensors have been widely developed for use in clinical diagnosis as point-of-care testing. However, most of them still suffer from inaccurate results, caused by the lack of biosensor stability under variable $\mathrm{pH}$ of biofluid samples; such as urine. Hence, the instability of $\mathrm{pH}$ variations is one of the key challenges for electrochemical biosensors. In this study, the development of gold nanoparticles-Prussian blue (AuNPs-PB) based screen-printed electrodes were investigated for their performance, in terms of electrochemical stability within various $\mathrm{pH}$ solutions.
\end{abstract}

Material and Methods: The AuNPs-PB modified screen-printed gold electrode (SPAUE) was developed and optimized using an electrode-position technique and cyclic voltammetry, respectively. As compared to PB modified SPAuE, the signal response of cyclic voltammograms at AuNPs-PB modified SPAuE was examined in a phosphate buffer solution with different $\mathrm{pH}$ values. The electrochemical stability of the modified SPAuE was considered on the invariability of the PB redox current in different $\mathrm{pH}$ solutions.

Results: The result revealed that stable current signals of PB in different $\mathrm{pH}$ solutions of the AuNPs-PB modified SPAuE showed good electrochemical stability, with a relative standard deviation (RSD) of oxidation and reduction peak currents being $1.0 \%$ and $1.1 \%$, respectively. The signal stability results exhibited over two and five times when compared to those of the PB modified SPAuE (without gold nanoparticles), which were $2.4 \%$ and $5.6 \%$ RSD, respectively.

Conclusion: The AuNPs-PB modified SPAuE provides a potentially alternative tool for the enhancement of electrochemical stability for use in medical biosensor applications.

Keywords: biosensor, electrochemical stability, gold nanoparticles, pH effect, point-of-care testing

Contact: Tonghathai Phairatana, Ph.D.

Department of Biomedical Sciences and Biomedical Engineering, Faculty of Medicine,

Prince of Songkla University, Hat Yai, Songkhla 90110, Thailand.

E-mail: tonghathai.p@psu.ac.th

This is an open access article under the CC BY-NC-ND license

(http://www.jhsmr.org/index.php/jhsmr/about/editorialPolicies\#openAccessPolicy). 


\section{Introduction}

Biosensors are analytical devices that operate based on their biological receptors being in direct contact with transducers. ${ }^{1}$ They have played an important role in medical diagnosis and patient monitoring, for providing quantitative or quasi-quantitative information to indicate a specific disease state or other physiological states in patients. This makes biosensors well suited to be applicable for a variety of diagnostic devices. Especially, electrochemical biosensors, which have gained great attention in the development of a compact analytical device for Point-of-Care testing. ${ }^{2-4}$

The challenge in developing an electrochemical biosensor for medical use is the requirement of high stability when testing in human biological fluid samples. Since samples from the human body have variable $\mathrm{pH}$ levels; particularly urine samples that have an unstable $\mathrm{pH}$ ranging from 4.5 to $7.8^{5}$, this could result in a decrease in electrochemical stability; leading to inaccurate clinical analysis. To overcome these issues, several studies have focused on the selection of proper materials, which is a crucial point (such as; nanomaterials, inorganic materials, and composite materials) that should be considered for use in the fabrication of electrochemical biosensors. ${ }^{6,7}$

Prussian blue (PB, Fe(III) $\left.{ }_{4}\left[\mathrm{Fe}(\mathrm{II})(\mathrm{CN})_{6}\right]_{3}\right)$, a mixedvalence ferric (III) and a hexacyanoferrate (II) compound, is an inorganic material ${ }^{8}$, which has been widely used as an electron-transfer mediator in sensors and biosensors; especially electrochemical biosensors; such as, enzymatic biosensors $^{9,10}$ and immunosensors. ${ }^{7,11}$ for citrus canker diagnosis. The immunosensor fabrication was based on the sequential electrodeposition of PB. The development of PBbased electrochemical sensors using an electrodeposition technique is an interesting strategy; as it can provide a simple, low cost, and highly reproducible method for the direct deposition of a PB film on an electrode. ${ }^{12}$ Nevertheless, the crucial issue of PB-based electrochemical sensors is the instability of PB film deposited on the electrode surface when using apparently neutral and alkaline $\mathrm{pH}^{9,13}$ This results in a reduction in the stability of the electrochemical PB response signals. ${ }^{14,15}$ Therefore, an improvement in terms of electrochemical stability is required.

For the most part, PB has been utilized in combination with other materials to enhance its stability ${ }^{15,16}$, and as of recently, gold nanoparticles (AuNPs) have become more of a focus point in biosensors, due to their properties; which include a large, specific surface area with high conductivity. ${ }^{17}$ Additionally, the use of AuNPs incorporated PB-based electrochemical biosensors has been reported to enhance the PB redox signals along with the sensitivity of biosensor. ${ }^{11,18,19}$ However, the study of electrochemical stability in various $\mathrm{pH}$ for a PB in combination with AuNPs has not been investigated.

The use of screen-printing technology for the fabrication of biosensors has considerably increased, with a large number of literature in clinical applications being studied. ${ }^{20,21}$ This technology is likely to be the most economical method for developing a disposable biosensor. This is due to its advantages; such as, low cost, ease of operation, and high reproducibility for biosensor modification.

To the best of our knowledge, this is the first time that the stability of AuNPs-PB modified screen-printed gold electrodes (SPAUEs) has been investigated under different $\mathrm{pH}$ buffer solutions. Herein, the purpose of this work was to develop a PB in combination with AuNPs modified on SPAuEs, for the improvement of electrochemical stability in $\mathrm{pH}$ variations for use in clinical applications. A AuNPs-PB modified SPAuE was developed by applying electrodeposition. Experimental parameters involved in PB electrodeposition; including, concentrations of $\mathrm{K}_{3}\left[\mathrm{Fe}(\mathrm{CN})_{6}\right]$ and $\mathrm{FeCl}_{3}$ as well as a number of scan cycles during the electrodeposition were optimized. The morphologies and electrochemical behaviors of both PB modified SPAuEs, with and without AuNPs, were characterized. Finally, the electrochemical stability of the AuNPs-PB film modified with 
SPAuE in different $\mathrm{pH}$ solutions was investigated through $\mathrm{PB}$ redox signals obtained from cyclic voltammetry.

\section{Material and Methods}

Potassium ferricyanide $\left(\mathrm{K}_{3}\left[\mathrm{Fe}(\mathrm{CN})_{6}\right]\right.$, Sigma-Aldrich, Germany), iron (III) chloride ( $\mathrm{FeCl}_{3}$, Sigma-Aldrich, Germany), potassium chloride (KCl, Ajax Finechem, USA), hydrochloric acid $(\mathrm{HCl}, \mathrm{RCl}$ Labscan, Thailand), and Hydrogen tetrachloroaurate(III) hydrate ( $\mathrm{HAuCl}_{4}$, Acros Organics $^{\mathrm{TW}}$, Belgium) were used as received. Sodium dihydrogen phosphate monohydrate $\left(\mathrm{NaH}_{2} \mathrm{PO}_{4} \cdot \mathrm{H}_{2} \mathrm{O}\right)$ and di-sodium hydrogen phosphate dihydrate $\left(\mathrm{Na}_{2} \mathrm{HPO}_{4} \cdot 2 \mathrm{H}_{2} \mathrm{O}\right)$, substances used to prepare a phosphate buffer, were obtained from Merck, Germany. All aqueous solutions were prepared using a Milli-Q purified water (resistivity $\geq 18 \mathrm{M} \Omega \mathrm{cm}$, Millipore).

All electrochemical methods were performed using a potentiostat $\mu$ Autolab PGSTAT204, with the computercontrolled by NOVA 2.1.4 software. Screen-printed gold electrodes (SPAuEs, DRP-250AT) were from Metrohm, the Netherlands. Scanning electron microscope images were achieved by a Tabletop SEM (TM3030Plus, Hitachi).
Initially, the electrode-position of the PB film on a gold electrode surface was conducted in the same manner as the study of Haji-Hashemi et al., 2018. ${ }^{11}$ Briefly, the PB film was electrochemically formed by immersing it in an aqueous solution, containing $100 \mathrm{mmol} \mathrm{L}^{-1} \mathrm{KCl}, 10 \mathrm{mmol}$ $\mathrm{L}^{-1} \mathrm{HCl}, \mathrm{K}_{3}\left[\mathrm{Fe}(\mathrm{CN})_{6}\right]$, and $\mathrm{FeCl}_{3}$, at different concentrations. The cyclic voltammetry was performed with a potential range of -0.20 to $+1.0 \mathrm{~V}$, at a scan rate of $50 \mathrm{mV} \mathrm{s}^{-1}$. Different concentrations of $\mathrm{K}_{3}\left[\mathrm{Fe}(\mathrm{CN})_{6}\right]$ and $\mathrm{FeCl}_{3}$ as well as the number of electrodeposited scan cycles were optimized. As seen in Figure 1, AuNPs-PB film on a SPAuE (AuNPs-PB/ SPAUE) was prepared in a solution containing the optimal concentrations of $\mathrm{K}_{3}\left[\mathrm{Fe}(\mathrm{CN})_{6}\right]$, and $\mathrm{FeCl}_{3} ; 100.0 \mathrm{mmol}$ $\mathrm{L}^{-1} \mathrm{KCl}, 10.0 \mathrm{mmol} \mathrm{L}^{-1} \mathrm{HCl}$, and $0.50 \mathrm{mmol} \mathrm{L}^{-1} \mathrm{HAuCl}_{4}$ (a chemical compound containing AuNPs), using cyclic voltammetric scanning between -0.20 and $+1.0 \mathrm{~V}$ for 20 cycles, at a scan rate of $50 \mathrm{mV} \mathrm{s}^{-1}$. After this step, the AuNPs-PB/SPAuE was rinsed with de-ionized water and dried with nitrogen gas. For comparison, a PB/SPAuE was fabricated using the same methods; but without the addition of $\mathrm{HAuCl}_{4}$.

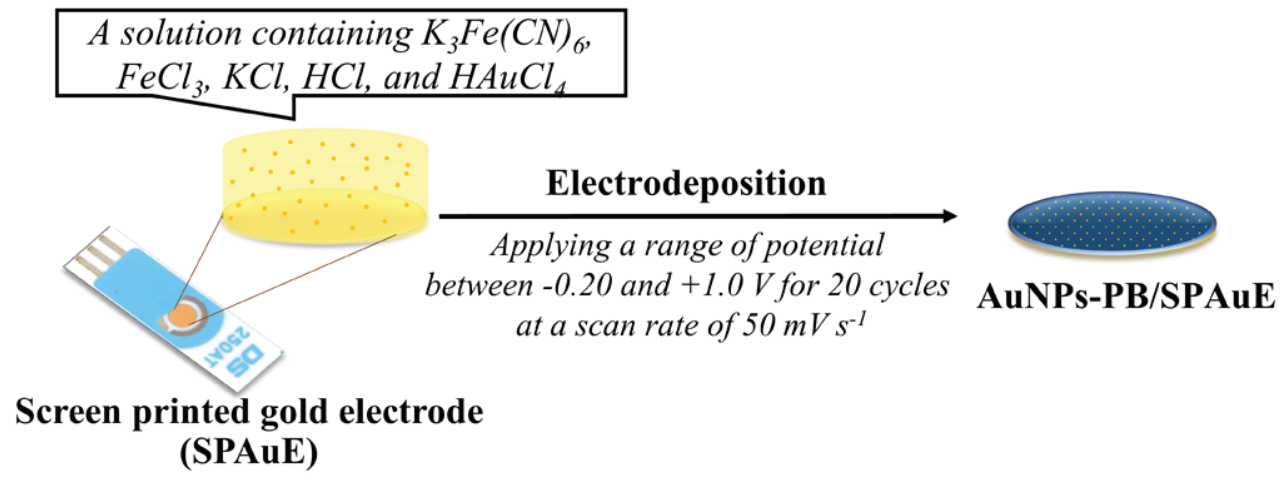

AuNPs-PB=gold-nanoparticles-Prussian blue, SPAuE=screen-printed gold electrode, AuNPs-PB/SPAuE=gold-nanoparticles-Prussian blue modified screen-printed gold electrode

Figure 1 Schematic illustration showing the electrodeposition of the AuNPs-PB film on the SPAuE surface 
In the process of $\mathrm{PB}$ electrodeposition, two main parameters could affect the PB films properties; i.e., the concentrations of $\mathrm{K}_{3}\left[\mathrm{Fe}(\mathrm{CN})_{6}\right]$ and $\mathrm{FeCl}_{3}$ that were used to activate the PB films and the scan number of cyclic voltammetry. Both $\mathrm{K}_{3}\left[\mathrm{Fe}(\mathrm{CN})_{6}\right]$ and $\mathrm{FeCl}_{3}$ at the concentrations of $0.25,0.50$, and $1.0 \mathrm{mmol} \mathrm{L}^{-1}$ were evaluated. Simultaneously, the number of scan cycles at 10, 20 , and 30 cycles were also investigated. The PB surface coverage $(\Gamma)$ could estimate the electroactive areas of PB cover on the electrode surface via calculation of the following equation: ${ }^{22}$

$$
\Gamma=\mathrm{Q} / \mathrm{nFA}
$$

Wherein, $Q$ is the charge achieved by the anodic peak of the PB signal; $n$ is the number of electrons transferred in the reaction $(n=1), F$ is Faraday's constant $\left(96,485 \mathrm{C} \mathrm{mol}^{-1}\right)$, and $\mathrm{A}$ is the area of the working electrode $\left(0.126 \mathrm{~cm}^{2}\right)$. The optimal condition chosen for further study was the one that obtained the maximum current signal of cyclic voltammogram, and the maximum PB electroactive area (the highest values of $\Gamma$ ).

To evaluate the electrochemical behaviors for the optimization studies and $\mathrm{pH}$ effect test, cyclic voltammetry was performed at a scan rate of $50 \mathrm{mV} \mathrm{s}^{-1}$. All measurements were carried out in a $100 \mathrm{mmol} \mathrm{L}^{-1}$ phosphate buffer solution (PBS) containing $50 \mathrm{mmol} \mathrm{L}^{-1}$ $\mathrm{KCl}$, as a supporting electrolyte.

To investigate the electrochemical stability in $\mathrm{pH}$ effect, phosphate buffers used as physiological fluids in the human body; especially, those being the most dominant urinary buffer ${ }^{23,24}$, were prepared by adjusting the $\mathrm{pH}$ to 5.80 , $6.30,6.80,7.00,7.40$, and 8.0 by adding $50 \mathrm{mmol} \mathrm{L}^{-1} \mathrm{KCl}$. The resulting oxidation and reduction peak current signals of $\mathrm{PB}$ at the $10^{\text {th }}$ cyclic voltammogram, which provided stable PB signals for each pH condition, were considered.

\section{Results}

The concentrations of $\mathrm{K}_{3}\left[\mathrm{Fe}(\mathrm{CN})_{6}\right], \mathrm{FeCl}_{3}$ and the number of electrodeposited scan cycles were further studied. After PB electrodeposition, the obtained cyclic voltammograms showed the redox peak currents of PB; as seen in Figure 2. At $0.25 \mathrm{mmol} \mathrm{L}^{-1} \mathrm{~K}_{3}\left[\mathrm{Fe}(\mathrm{CN})_{6}\right]$ and $0.25 \mathrm{mmol} \mathrm{L}^{-1} \mathrm{FeCl}_{3}$, the current response was higher when increasing the number of scans (Figure 2a). Cyclic voltammograms at the conditions of $0.50 \mathrm{mmol} \mathrm{L}^{-1}$ and 1.0 mmol L ${ }^{-1}$ of both $\mathrm{K}_{3}\left[\mathrm{Fe}(\mathrm{CN})_{6}\right.$ ] and $\mathrm{FeCl}_{3}$ showed similar $\mathrm{PB}$ signals, for which the maximum current response was found at 20 scans. At 10 scans, the current signal had the lowest response; whereas, it can be observed that a decrease in current response and wide displacement between the oxidation and reduction peak potentials occurred at 30 scans (Figure $2 \mathrm{~b}$ and $2 \mathrm{c}$, respectively).

In Figure 2d, the three different concentrations; with varying scan numbers for PB electrode-position, were plotted and compared by the calculation of the PB surface coverage $(\Gamma) . \Gamma$ of 10,20 , and 30 scans at 0.25 $\mathrm{mmol} \mathrm{L}{ }^{-1}$ were calculated to be $0.29,0.40$, and $0.71 \mathrm{nmol}$ $\mathrm{cm}^{-2}$, respectively. The $\Gamma$ value is likely to increase gradually when increasing the number of scans. $\Gamma$ values at 10, 20, and 30 scans were $0.67,1.22$, and $1.06 \mathrm{nmol} \mathrm{cm}^{-2}$ for 0.50 $\mathrm{mmol} \mathrm{L}^{-1}$ and $0.79,1.04$, and $1.02 \mathrm{nmol} \mathrm{cm}{ }^{-2}$ for $1.00 \mathrm{mmol}$ $\mathrm{L}^{-1}$. It was observed that the greatest $\Gamma$ values were found at the concentration of $0.50 \mathrm{mmol} \mathrm{L}^{-1}$, and the number of electrodeposition scans at 20 cycles. Therefore, this optimal condition was chosen for the fabrication of the AuNPs-PB/ SPAuE in addition to the PB/SPAuE.

The surface morphologies of the PB film (Figure 3a) and the AuNPs-PB film (Figure 3b) modified on SPAuE were investigated using SEM. The PB film showed small sphere-like particles homogeneously dispersed on the SPAuE surface; whereas, the AuNPs-PB film was rough and exhibited many nanoparticles embedded within the PB film. 

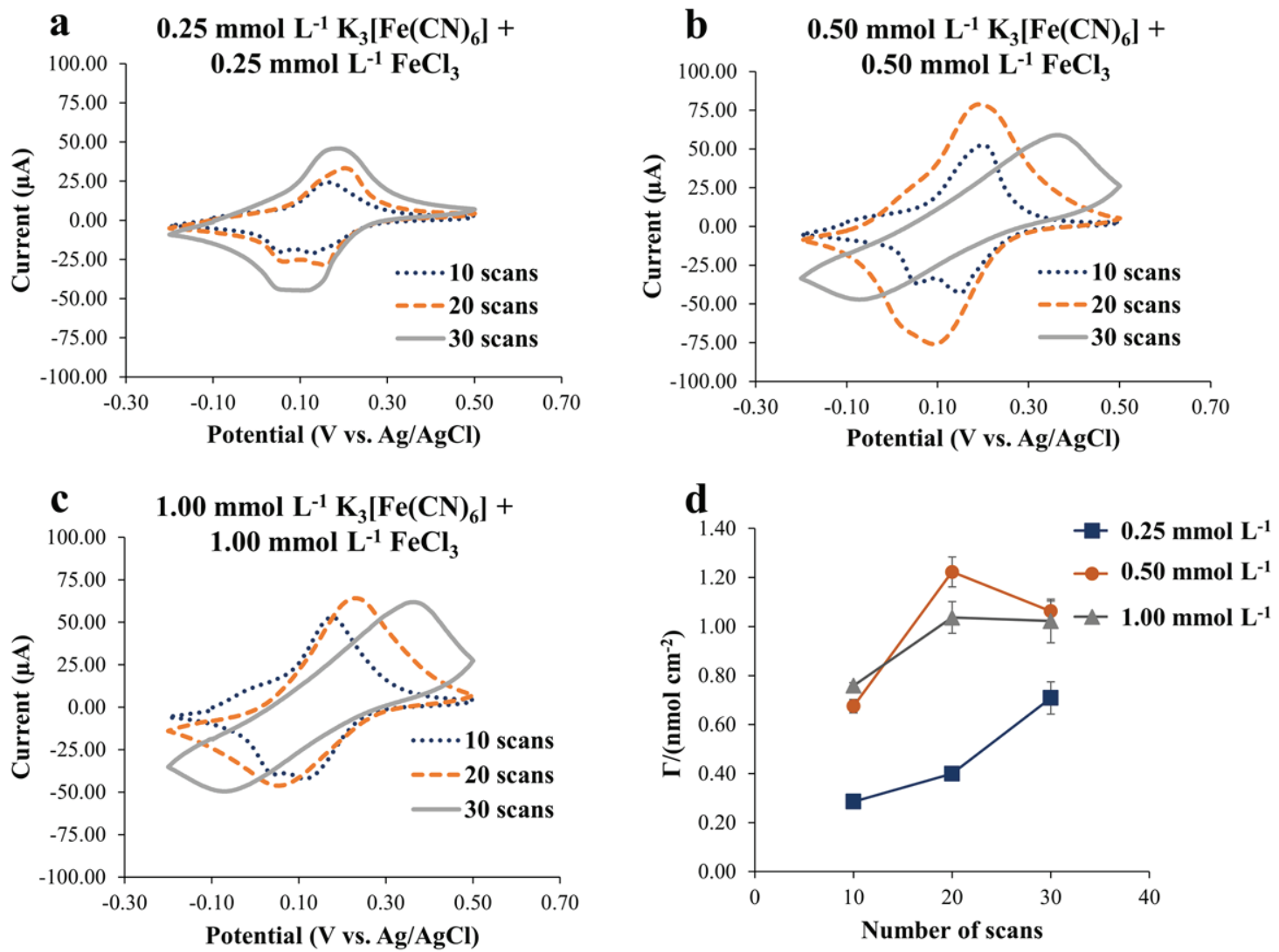

$\mathrm{PB}=$ Prussian blue, $\mathrm{PBS}=$ phosphate buffer solution, $\mathrm{KCl}=$ potassium chloride, $\mathrm{K}_{3}\left[\mathrm{Fe}(\mathrm{CN})_{6}\right]=$ potassium ferricyanide, $\mathrm{FeCl}=$ =iron (III) chloride

Figure 2 Cyclic voltammograms of the PB modified gold electrode in $100 \mathrm{mmol} \mathrm{L}^{-1} \mathrm{PBS}$ (pH 7.0), containing $50.0 \mathrm{mmol}$ $\mathrm{L}^{-1} \mathrm{KCl}$, when varying the number of scan cycles during the PB electrodeposition process; at different concentrations of $\mathrm{K}_{3}\left[\mathrm{Fe}(\mathrm{CN})_{6}\right]$ and $\mathrm{FeCl}_{3}$; (a) $0.25 \mathrm{mmol} \mathrm{L}^{-1}$, (b) $0.50 \mathrm{mmol} \mathrm{L}^{-1}$, and (c) $1.0 \mathrm{mmol} \mathrm{L}^{-1}$. (d) The plot of surface coverages when varying concentrations of $\mathrm{K}_{3}\left[\mathrm{Fe}(\mathrm{CN})_{6}\right]$ and $\mathrm{FeCl}_{3}$ versus the number of scan cycles.

The PB film, with and without AuNPs, were electrochemically characterized using cyclic voltammetry; as shown in Figure 4. Before modification, cyclic voltammograms of SPAuE 1 and SPAuE 2 showed no obvious redox peaks (Figure 4, inset). The redox peaks obviously occurred when coating the PB film (PB/SPAuE 1) and the AuNPs-PB film (AuNPs-PB/SPAuE 2). The AuNPs-PB/SPAuE 2 showed a higher current signal than that of the PB/SPAuE.
Moreover, the oxidation (anodic) and the reduction (cathodic) peaks of both PB/SPAuE and AuNPs-PB/SPAuE were observed in the same potentials; at $0.058 \mathrm{~V}$ and -0.042 $\mathrm{V}$, respectively. The difference between the oxidation and reduction peak potentials (peak-to-peak separation, $\Delta E p$ ) were calculated to be $100 \mathrm{mV}$. The values of the oxidation $\left(I_{p a}\right)$, reduction $\left(I_{p c}\right)$ peak currents, and the $I_{p c} \Lambda_{p a}$ ratios were also examined; as shown in Table 1. 

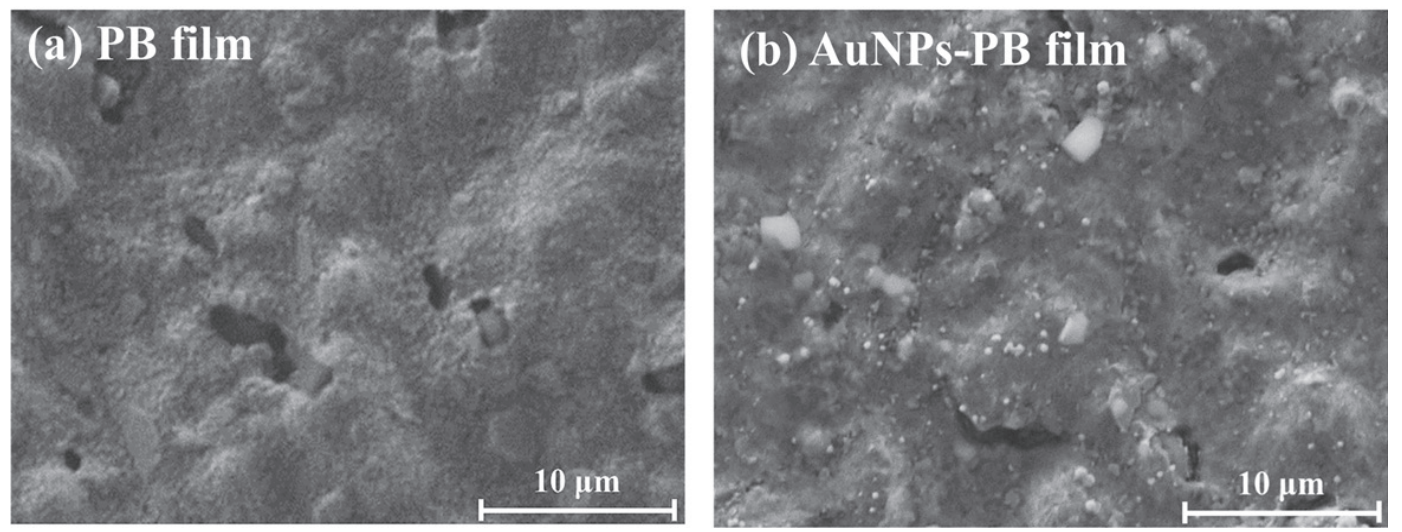

SEM=scanning electron microscopy, SPAuE=screen-printed gold electrode, PB=Prussian blue, AuNPs-PB/SPAuE=gold-nanoparticlesPrussian blue modified screen-printed gold electrode

Figure 3 SEM images of the modified SPAuE: (a)PB/SPAuE, and (b)AuNPs-PB/SPAuE

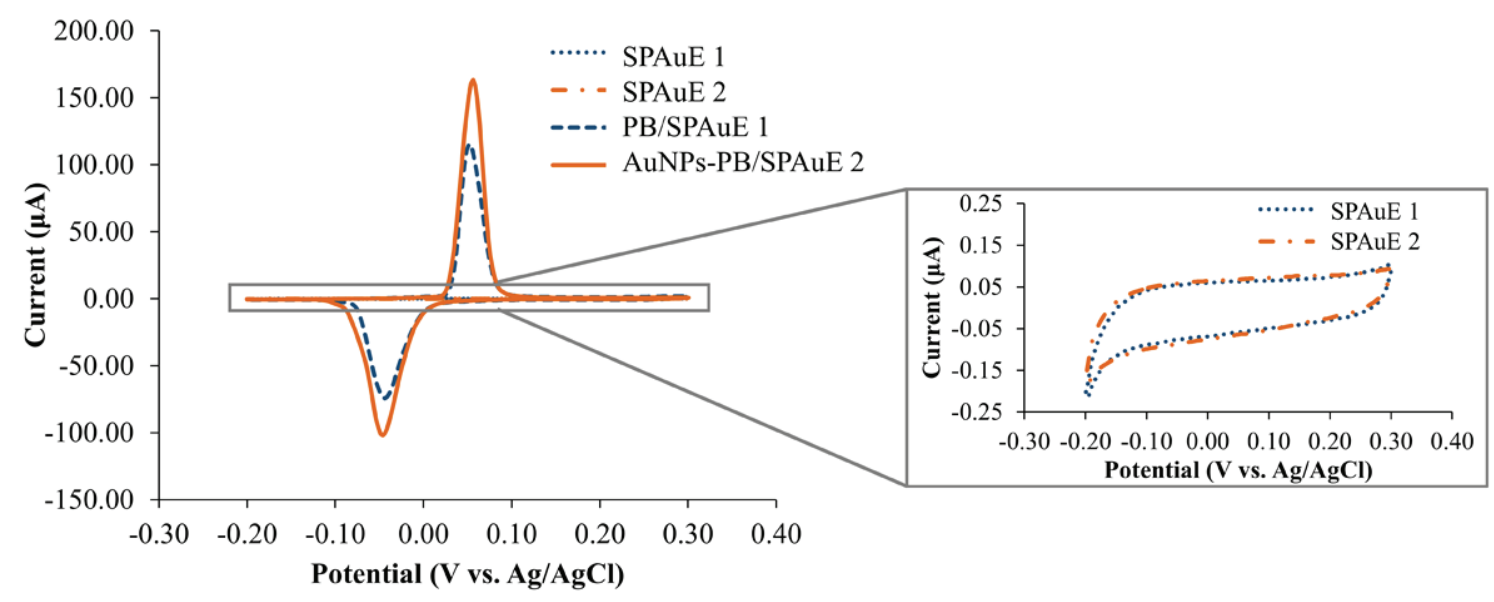

SPAuE=screen-printed gold electrode, PB/SPAuE=Prussian blue modified screen-printed gold electrode, AuNPs-PB/SPAuE=goldnanoparticles-Prussian blue modified screen-printed gold electrode, $\mathrm{V}=$ voltage, $\mathrm{Ag} / \mathrm{AgCl}=$ silver/silver-chloride

Figure 4 Cyclic voltammograms of SPAuE modification with PB films and AuNPs-PB films in $100 \mathrm{mmol} \mathrm{L}^{-1} \mathrm{PBS}, \mathrm{pH} 7.0$ containing $50 \mathrm{mmol} \mathrm{L}^{-1} \mathrm{KCl}$, at a scan rate of $50 \mathrm{mV} \mathrm{s}^{-1}$ 
Table 1 Values of $\mathrm{I}_{\mathrm{pa}}, \mathrm{I}_{\mathrm{pc}}$, and $\mathrm{I}_{\mathrm{pc}} \Lambda_{\mathrm{pa}}$ ratio obtained from cyclic voltammograms of the PB/SPA

\begin{tabular}{llll}
\hline Electrodes & $\mathrm{I}_{\mathrm{pa}}(\boldsymbol{\mu A})$ & $\mathrm{I}_{\mathrm{pc}}(\boldsymbol{\mu A})$ & $\mathrm{I}_{\mathrm{pc}} / \mathrm{I}_{\mathrm{pa}}$ ratio \\
\hline PB/SPAuE 1 & 110.17 & -72.96 & 0.66 \\
AuNPs-PB/SPAuE 2 & 166.36 & -112.42 & 0.67 \\
\hline
\end{tabular}

$\mathrm{PB} / \mathrm{SPAuE}=$ Prussian blue modified screen-printed gold electrode AuNPs-PB/SPAuE=gold-nanoparticles-Prussian blue modified screen-printed gold electrode

a

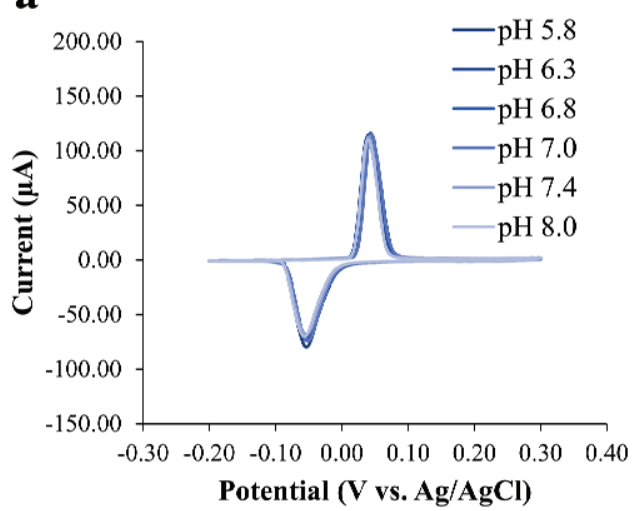

c

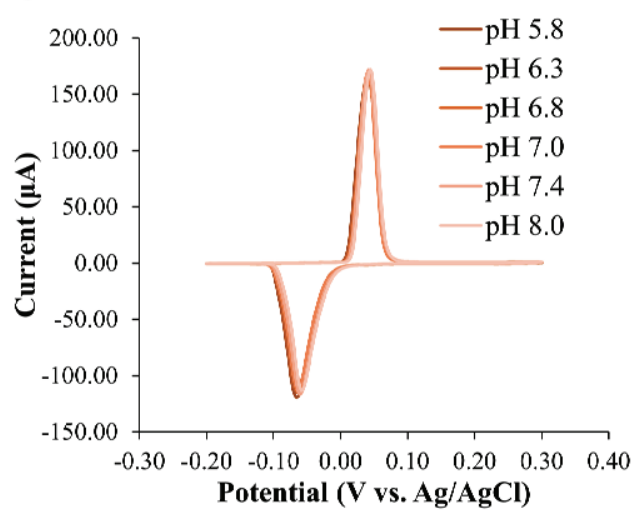

The pH effect on the electrochemical behavior of PB film and AuNPs-PB film

The $\mathrm{pH}$ effect of PB and AuNPs-PB deposited on SPAuE was investigated in PBS solutions at different $\mathrm{pH}$ values, i.e., 5.80, 6.30, 6.80, 7.00, 7.40, and 8.00. Cyclic voltammograms of the PB/SPAuE (Figure 5a) and the AuNPs-PB/SPAuE (Figure 5c) showed no change in the relocation of oxidation and reduction potentials of $\mathrm{PB}$. The redox peak currents obtained from the PB/SPAuE and the
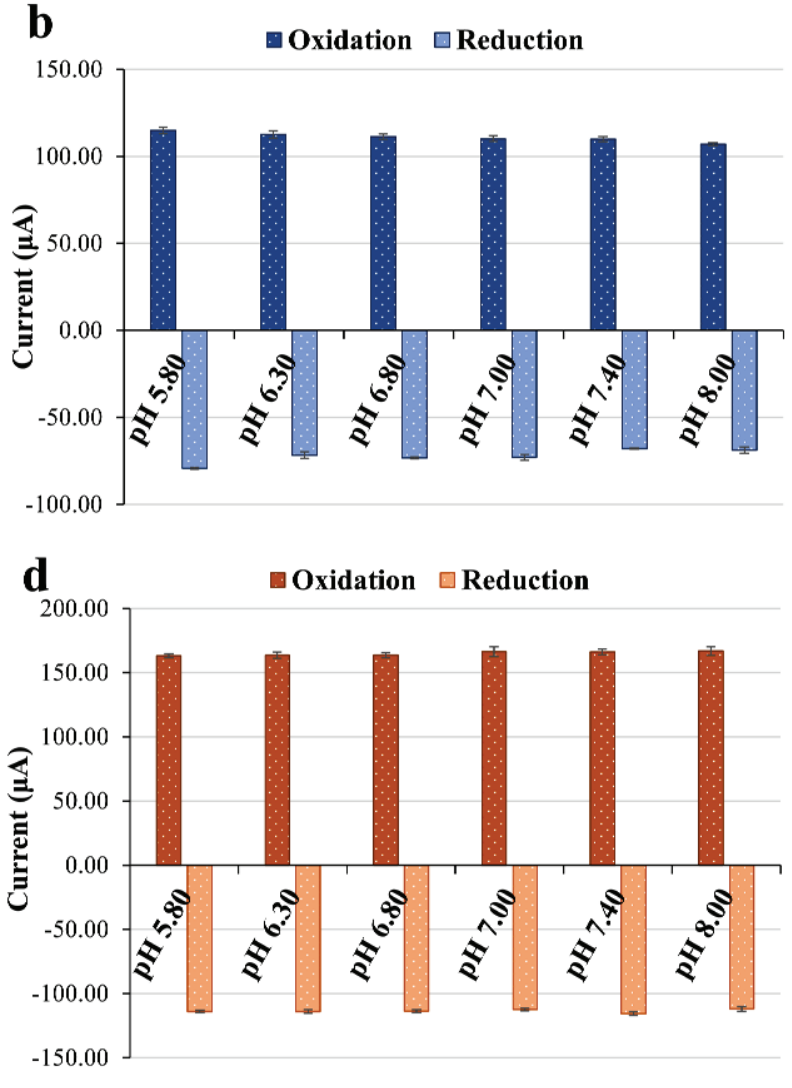

PB/SPAuE=Prussian blue modified screen-printed gold electrode, AuNPs-PB/SPAuE=gold-nanoparticles-Prussian blue modified screenprinted gold electrode, $\mathrm{PBS}=$ phosphate buffer solution, $\mathrm{KCl}=$ potassium chloride, $\mathrm{V}=\mathrm{voltage}, \mathrm{Ag} / \mathrm{AgCl}=\mathrm{silver} /$ silver-chloride

Figure 5 Cyclic voltammograms of (a) PB/SPAuE and (c) AuNPs-PB /SPAuE in $100 \mathrm{mmol} \mathrm{L}^{-1} \mathrm{PBS}$ at various $\mathrm{pH}$ from 5.80-8.00, containing $50 \mathrm{mmol} \mathrm{L}^{-1} \mathrm{KCl}$, at the scan rate of $50 \mathrm{mV} \mathrm{s}^{-1}$. The plots of reduction and oxidation current signals were obtained in $100 \mathrm{mmol} \mathrm{L}^{-1} \mathrm{PBS}$ versus $\mathrm{pH}$ values at (b) PB/SPAuE, and (d) AuNPs-PB/ SPAuE $(n=3)$. 
AuNPs-PB/SPAuE at different $\mathrm{pH}$ solutions are shown in the bar graph (Figure $5 b$ and Figure $5 d$, respectively). In the $\mathrm{PB} / \mathrm{SPAuE}$, the peak currents at $\mathrm{pH} 5.80,6.30,6.80,7.00$, 7.40, and 8.00 were $114.9 \pm 1.8 \mu \mathrm{A}, 112.5 \pm 2.2 \mu \mathrm{A}, 111.3 \pm 1.5$ $\mu \mathrm{A}, 110.2 \pm 1.7 \mu \mathrm{A}, 109.8 \pm 1.5 \mu \mathrm{A}$, and 106.97 $\pm 0.84 \mu \mathrm{A}$ for the oxidation peaks, and $-79.27 \pm 0.51 \mu \mathrm{A},-71.7 \pm 1.9$ $\mu \mathrm{A},-73.2 \pm 1.7 \mu \mathrm{A},-73.0 \pm 1.7 \mu \mathrm{A},-67.9 \pm 1.3 \mu \mathrm{A}$, and $-68.8 \pm 1.8 \mu \mathrm{A}$ for the reduction peaks. The average oxidation and reduction peak currents had a relative standard deviation (RSD) of $2.4 \%$ and $5.6 \%$, respectively. At the AuNPs-PB/SPAuE, the redox peak currents were 163.1 $\pm 1.6 \mu \mathrm{A}, 163.6 \pm 1.0 \mu \mathrm{A}, 163.6 \pm 2.1 \mu \mathrm{A}, 166.0 \pm 1.4 \mu \mathrm{A}$, $166.4 \pm 1.0 \mu \mathrm{A}$, and $166.9 \pm 1.8 \mu \mathrm{A}$ for the oxidation peaks, and $-113.96 \pm 0.92 \mu \mathrm{A},-113.9 \pm 1.4 \mu \mathrm{A},-113.7 \pm 1.1 \mu \mathrm{A}$, $-112.4 \pm 1.1 \mu \mathrm{A},-115.5 \pm 1.4 \mu \mathrm{A}$, and $-112.0 \pm 1.9 \mu \mathrm{A}$ for the reduction peaks. The results showed stable, current signals in all $\mathrm{pH}$ solutions with the RSD of oxidation and reduction peak currents being $1.0 \%$ and $1.1 \%$, respectively.

\section{Discussion}

In this study, it was demonstrated that the AuNPsPB film deposited on SPAuE could contribute to the improvement of the electrochemical performance of the PB signal. Initially, the optimization study was carried out to determine the optimal conditions in the process of PB electrodeposition. As per the results, at $0.25 \mathrm{mmol} \mathrm{L}^{-1}$ $\mathrm{K}_{3}\left[\mathrm{Fe}(\mathrm{CN})_{6}\right]$ and $0.25 \mathrm{mmol} \mathrm{L}^{-1} \mathrm{FeCl}_{3}$, the current response was higher when increasing the number of scans. This is due to the larger electroactive site of PB on the gold electrode surface. Moreover, it was noted that two reduction peaks were observed for every scan (Figure 2a). Similarly, the couple reduction peaks at $0.50 \mathrm{mM} \mathrm{K} \mathrm{K}_{3}\left[\mathrm{Fe}(\mathrm{CN})_{6}\right]$ and $0.50 \mathrm{mmol} \mathrm{L}^{-1} \mathrm{FeCl}_{3}$ (Figure 2b) as well as $1.0 \mathrm{mM}$ $\mathrm{K}_{3}\left[\mathrm{Fe}(\mathrm{CN})_{6}\right]$ and $1.0 \mathrm{mmol} \mathrm{L}^{-1} \mathrm{FeCl}_{3}$ (Figure $2 \mathrm{c}$ ) were also found at 10 cycles. The electrochemical behavior, showing at a peak at approximately $0.15 \mathrm{~V}$, is most likely massive precipitation of $\mathrm{PB}$ occurring in the process of the reduction of $\mathrm{Fe}^{3+}$ to $\mathrm{Fe}^{2+}$, as was discussed in Isfahani et al., 2019. ${ }^{25}$ The mentioned mechanism is probably due to the reaction of the $(\mathrm{Fe}(\mathrm{III})[\mathrm{Fe}(\mathrm{III})(\mathrm{CN})]]$ ) complex with the conductive material; as shown in reaction (2) and (3). However, the behavior for the concentrations of 0.50 and $1.0 \mathrm{mmol} \mathrm{L}^{-1}$ at 20 and 30 scan cycles disappeared. This could indicate that electrodeposited PB films might be stable under these conditions. Generally, the redox peaks obtained from a PB transformation to Prussian white are also shown according to the reaction (4):

$$
\begin{aligned}
& \mathrm{Fe}^{3+}+\left[\mathrm{Fe}(\mathrm{III})(\mathrm{CN})_{6}\right]^{3-} \leftrightharpoons \mathrm{Fe}(\mathrm{III})\left[\mathrm{Fe}(\mathrm{III})(\mathrm{CN})_{6}\right] \\
& 3 \mathrm{Fe}(\mathrm{III})\left[\mathrm{Fe}(\mathrm{III})(\mathrm{CN})_{6}\right]+\mathrm{Fe}^{3+}+3 \mathrm{e}^{-} \leftrightharpoons \mathrm{Fe}(\mathrm{III})_{4}\left[\mathrm{Fe}(\mathrm{II})(\mathrm{CN})_{6}\right]_{3} \\
& \mathrm{Fe}(\mathrm{III})\left[\mathrm{Fe}(\mathrm{II})(\mathrm{CN})_{6}\right]_{3} \leftrightharpoons \mathrm{K}_{4} \mathrm{Fe}(\mathrm{II})_{4}\left[\mathrm{Fe}(\mathrm{II})(\mathrm{CN})_{6}\right]_{3} \\
& \text { (Prussian blue) } \quad \text { (Prussian white) }
\end{aligned}
$$

In addition, at $0.50 \mathrm{mmol} \mathrm{L}^{-1}$ (Figure 2b) and $1.0 \mathrm{mmol} \mathrm{L}^{-1}$ (Figure 2c) of both $\mathrm{K}_{3}\left[\mathrm{Fe}(\mathrm{CN})_{6}\right]$ and $\mathrm{FeCl}_{3}$ exhibited similar PB signals, for which the maximum current response was at 20 scan cycles. At $0.50 \mathrm{mmol}^{-1}$ for 20 scans showed a higher current response than at 1.0 $\mathrm{mmol} \mathrm{L}^{-1}$. This might be because PB forming when using the higher concentrations (at $1.0 \mathrm{mmol} \mathrm{L}^{-1} \mathrm{~K}_{3}\left[\mathrm{Fe}(\mathrm{CN})_{6}\right]$ and $\mathrm{FeCl}_{3}$ ) could affect and hinder the electron transfer. This lead to a slight decrease in the current response and the broader expanse between the oxidation and reduction peak as compared to that of at $0.50 \mathrm{mmol} \mathrm{L}^{-1}$ for 20 scans. At 10 scans, the current signal had the lowest response, because the amount of the electroactive site of PB might not be sufficient to cover the whole electrode surface. On the other hand, at 30 scans, in cases of $0.50 \mathrm{mmol} \mathrm{L}^{-1}$ and $1.0 \mathrm{mmol} \mathrm{L}^{-1}$, it showed a decrease in current response and wide peak-to-peak separations of $428 \mathrm{mV}$ and 450 $\mathrm{mV}$, respectively. This indicates that at 30 scans of both, it exhibited hinder reversible electron-transfer to the electrode surface when compared with at 10 and 20 scans of their concentration. This is because the PB layer may have an excessive amount of PB; thus, blocking the electron transfer. This leads to a decrease in current response, and has 
wider displacement between the oxidation and reduction peak potentials. The surface coverages $(\Gamma)$ at varying concentrations of $\mathrm{K}_{3}\left[\mathrm{Fe}(\mathrm{CN})_{6}\right.$ ] and $\mathrm{FeCl}_{3}$ versus the number of scan cycles (Figure $2 \mathrm{~d}$ ) revealed that the $\Gamma$ values of $0.25 \mathrm{mmol} \mathrm{L}^{-1}$ was higher with an increase in the number of electrodeposited scan cycles. This was due to the larger amounts of PB electroactive areas on the gold electrode surface; whereas, the highest $\Gamma$ values of at $0.50 \mathrm{mmol} \mathrm{L}^{-1}$ and $1.0 \mathrm{mmol} \mathrm{L}^{-1}$ were found at 20 scan cycles. The amount of PB might not be adequate at 10 scans and might be excessive at 30 scans, leading to the decrease of their $\Gamma$ value. However, at $0.50 \mathrm{mmol} \mathrm{L^{-1 }}$ with 20 electrodeposited scan cycles provided the greatest $\Gamma$ values; indicating the highest PB electroactive areas. Therefore, $0.50 \mathrm{mmol} \mathrm{L}^{-1}$ of both $\mathrm{K}_{3}\left[\mathrm{Fe}(\mathrm{CN})_{6}\right]$ and $\mathrm{FeCl}_{3}$ with 20 electrodeposited scan cycles was the optimal condition in this study. This is because it exhibited the highest current response, and the highest PB electroactive areas.

It was found that the integrated AuNPs with the PB film could contribute to a greater PB signal, because the current response obtained from the AuNPs-PB/SPAuE was higher than the PB/SPAuE. It can explain that the AuNPs could provide high conductivity and a large surface area, leading to the enhancement of the electron transfer rate of the PB signal. ${ }^{11}$ The PB redox reaction on both modified SPAuE surfaces showed electrochemical behaviors called quasi-reversible reaction. This is because the $\mathrm{I}_{\mathrm{pc}} \Lambda_{\mathrm{pa}}$ ratio was less than 1, and their $\Delta \mathrm{Ep}$ were greater than $59 \mathrm{mV}$, as per the theoretical value for reversible reaction. ${ }^{26}$ Although, the electrochemical behaviors at the PB/SPAuE and the AuNPs-PB/SPAuE showed similar properties, the presence of AuNPs with the PB film provided an enhancement of the PB signal.

For electrochemical stability tests, cyclic voltammograms of the PB/SPAuE and the AuNPs-PB/SPAuE revealed no significant change in the relocation of oxidation and reduction potentials of PB. Although, the results could confirm the positional invariability of $\mathrm{PB}$ redox signals in various $\mathrm{pH}$ solutions, it is noted that the redox signals gradually decreased with higher $\mathrm{pH}$ solutions for the PB/ SPAuE. This led to greater RSD of the average oxidation and reduction peak currents of $2.41 \%$ and $5.61 \%$, respectively. This is because hydroxyl ions in higher $\mathrm{pH}$ solutions could break the Fe-CN-Fe bond of the PB film. ${ }^{27}$ Meanwhile, the results showed stable, current signals in all $\mathrm{pH}$ solutions for the AuNPs-PB/SPAuE, with the RSD of oxidation and reduction peak currents being $1.03 \%$ and $1.11 \%$, respectively. This could confirm that AuNPs embedded in PB film could contribute to the stability of the AuNPs-PB film. This is probably due to the stronger adsorption of PB, i.e. positively charged AuNPs can electrostatically attract negatively charged $\left[\mathrm{Fe}(\mathrm{CN})_{6}\right]^{3-/ 4-}$ during the PB formation on the gold electrode surface. This promotes better PB coating, which increases the stability of the PB film. Thus, it indicated that the AuNPs-PB/SPAuE exhibited excellent electrochemical stability, even after several electrochemical cycles at different $\mathrm{pH}$ values.

\section{Conclusion}

This study developed an AuNPs-PB modified SPAuE, using the electrodeposition technique via cyclic voltammetry. The optimal condition at a concentration of $0.50 \mathrm{mmol}^{-1}$ $\mathrm{K}_{3}\left[\mathrm{Fe}(\mathrm{CN})_{6}\right]$ and $\mathrm{FeCl}_{3}$, and the number of scans at 20 cycles was applied to fabricate the AuNPs-PB film during the electrodeposition process. The surface morphologies and the electrochemical performance of the AuNPs-PB/SPAuE was evaluated in comparison with a PB modified SPAuE without AuNPs. The AuNPs-PB/SPAuE exhibited higher PB redox signals, with a well-defined quasi-reversible reaction. The stability of AuNPs-PB/SPAuEs were tested in PBS, with various $\mathrm{pH}$ from 5.80 to 8.00. The presence of AuNPs in PB films not only enhances the redox signal of PB, but also improves the electrochemical stability in solutions with various $\mathrm{pH}$. The AuNPs-PB/SPAuE offers great potential for 
the stability of PB-based electrochemical biosensors as an attractive alternative for use in medical biosensors, including immunosensors for detection of breast cancer biomarkers and cardiac biomarkers.

\section{Acknowledgement}

We gratefully acknowledged the Graduate scholarship from Faculty of Medicine, Prince of Songkla University, Thailand. We would also like to thank the International Affairs Office of the Faculty of Medicine, Prince of Songkla University for editing the English of the manuscript.

\section{Conflict of interest}

There are no potential conflicts of interest to declare.

\section{References}

1. Thévenot DR, Toth K, Durst RA, Wilson GS. Electrochemical biosensors: recommended definitions and classification. Biosens Bioelectron 2001;16:121-31.

2. Vinoth S, Shalini Devi KS, Pandikumar A. A comprehensive review on graphitic carbon nitride based electrochemical and biosensors for environmental and healthcare applications. TrAC - Trends Anal Chem 2021;140:116274.

3. Yang A, Yan F. Flexible electrochemical biosensors for health monitoring. ACS Appl Electron Mater 2021;3:53-67.

4. Lee SX, Lim HN, Ibrahim I, Jamil A, Pandikumar A, Huang NM. Horseradish peroxidase-labeled silver/reduced graphene oxide thin film-modified screen-printed electrode for detection of carcinoembryonic antigen. Biosens Bioelectron 2017;89: 673-80.

5. Clarkson MR, Magee CN, Brenner BM. Laboratory assessment of kidney disease. In: Clarkson MR, Magee CN, Brenner BM, editors. Pocket companion to Brenner and Rector's the kidney. $8^{\text {th }}$ ed. London: Elsevier; 2011;p.21-41.

6. Chan KF, Lim HN, Shams N, Jayabal S, Pandikumar A, Huang NM. Fabrication of graphene/gold-modified screen-printed electrode for detection of carcinoembryonic antigen. Mater Sci Eng C 2016;58:666-74.

7. Wei S, Xiao H, Cao L, Chen Z. A label-free immunosensor based on graphene oxide/Fe304/Prussian blue nano- composites for the electrochemical determination of HBsAg. Biosensors 2020;10. doi: 10.3390/bios10030024.

8. Wu X, Cao M, Hu C, He X. Sonochemical synthesis of Prussian blue nanocubes from a single-source precursor. Cryst Growth Des 2006;6:26-8.

9. Zhang M, Hou C, Halder A, Ulstrup J, Chi Q. Interlocked graphene-Prussian blue hybrid composites enable multifunctional electrochemical applications. Biosens Bioelectron 2017;89:570-7.

10. Keihan AH, Ramezani Karimi R, Sajjadi S. Wide dynamic range and ultrasensitive detection of hydrogen peroxide based on beneficial role of gold nanoparticles on the electrochemical properties of prussian blue. J Electroanal Chem 2020;862: 114001.

11. Haji-Hashemi H, Habibi MM, Safarnejad MR, Norouzi P, Ganjali MR. Label-free electrochemical immunosensor based on electrodeposited Prussian blue and gold nanoparticles for sensitive detection of citrus bacterial canker disease. Sensors Actuators, B Chem 2018;275:61-8.

12. Baggio BF, Vicente C, Pelegrini S, Cid CCP, Brandt IS, Tumelero MA, et al. Morphology and structure of electrodeposited Prussian Blue and Prussian white thin films. Materials (Basel) 2019;12:15-21.

13. Zhao J, Yue P, Tricard S, Pang T, Yang Y, Fang J. Prussian blue (PB)/carbon nanopolyhedra/polypyrrole composite as electrode: a high performance sensor to detect hydrazine with long linear range. Sensors Actuators, B Chem 2017;251:706-12.

14. Ricci F, Amine A, Palleschi G, Moscone D. Prussian Blue based screen printed biosensors with improved characteristics of long-term lifetime and pH stability. Biosens Bioelectron 2002; 18:165-74.

15. Li Z, Chen J, Li W, Chen K, Nie L, Yao S. Improved electrochemical properties of prussian blue by multi-walled carbon nanotubes. J Electroanal Chem 2007;603:59-66.

16. Husmann S, Orth ES, Zarbin AJG. A multi-technique approach towards the mechanistic investigation of the electrodeposition of Prussian blue over carbon nanotubes film. Electrochim Acta 2019;312:380-91.

17. Saha K, Agasti SS, Kim C, Li X, Rotello VM. Gold nanoparticles in chemical and biological sensing. Chem Rev 2012;112:273979.

18. Kumar SS, Joseph J, Phani KL. Novel method for deposition of gold-prussian blue nanocomposite films induced by electro- 
chemically formed gold nanoparticles: characterization and application to electrocatalysis. Chem Mater 2007;19:4722-30.

19. Wang G, Chen L, Zhu Y, He X, Xu G, Zhang X. Prussian blue-Au nanocomposites actuated hemin/G-quadruplexes catalysis for amplified detection of DNA, $\mathrm{Hg} 2+$ and adenosine triphosphate. Analyst 2014;139:5297-303.

20. Arduini F, Micheli L, Moscone D, Palleschi G, Piermarini S, Ricci $F$, et al. Electrochemical biosensors based on nanomodified screen-printed electrodes: recent applications in clinical analysis. TrAC - Trends Anal Chem 2016;79:114-26.

21. Ahmed MU, Hossain MM, Safavieh M, Wong YL, Rahman IA, Zourob M, et al. Toward the development of smart and low cost point-of-care biosensors based on screen printed electrodes. Crit Rev Biotechnol 2016;36:495-505.

22. Salazar P, Martín M, González-Mora JL, González-Elipe AR. Application of Prussian Blue electrodes for amperometric detection of free chlorine in water samples using Flow Injection Analysis. Talanta 2016;146:410-6.

23. McNamara J, Worthley LI. Acid-base balance: part I. Physiology. Crit Care Resusc 2001;3:181-7.

24. Lee Hamm L, Simon EE. Roles and mechanisms of urinary buffer excretion. Am J Physiol - Ren Fluid Electrolyte Physiol 1987;253:595-605.

25. Isfahani VB, Dizaji, Hamid Rezagholipour Memarian N, Arab A. Electrodeposition of Prussian Blue films: study of deposition time effect on electrochemical properties. Mater Res Express 2019;27:096449.

26. Wang J. Analytical electrochemistry. $2^{\text {nd }}$ ed. New York: Wiley-VCH; 2000;p.223

27. Karyakin AA. Prussian blue and its analogues: electrochemistry and analytical applications. Electroanalysis 2001;13:831-5. 